\section{Propofol anaesthesia in paediatric ambulatory patients: a comparison with thiopentone and halothane}

Raafat S. Hannallah MD FRCPC, John T. Britton MD, Patrick G. Schafer MD, Ramesh I. Patel MD, Janet M. Norden MSN
The purpose of this study was to evaluate the haemodynamic changes during induction, as well as the speed and quality of recovery when propofol (vs thiopentone and/or halothane) was used for induction and maintenance of anaesthesia in paediatric outpatients. One hundred unmedicated children, 3-12-yr-old, scheduled for ambulatory surgery were studied. The most common surgical procedures performed were eye muscle surgery (42\%), plastic surgery (21\%), dental restoration (15\%), and urological procedures (15\%). The children were randomized to an anaesthetic regimen for induction/maintenance as follows: propofol/propofol infusion; propofol/halothane; thiopentone/halothane; halothane for both induction and maintenance. Succinylcholine $1.5 \mathrm{mg} \cdot \mathrm{kg}^{-1}$ was used to facilitate tracheal intubation and $\mathrm{N}_{2} \mathrm{O} / \mathrm{O}_{2}$ were used as the carrier gases in each case. All maintenance drugs were titrated according to the clinical response of the patient to prevent movement and/or maintain BP $\pm 20 \%$ of baseline. Two patients (4\%) who received propofol expressed discomfort during injection. The mean propofol dose required to prevent movement was $267 \pm 83$ $\mu \mathrm{g} \cdot \mathrm{kg}^{-l} \cdot \mathrm{min}^{-1}$. The overall pattern of haemodynamic changes, as well as awakening (extubation) times were not different among the four groups. Children who received propofol

\section{Key words}

ANAESTHESIA: paediatric;

ANAESTHETICS, INTRAVENOUS: propofol, thiopentone; ANAESTHETICS, INHALATIONAL: halothane.

From the Departments of Anesthesiology and Paediatrics, Children's National Medical Center and George Washington University Medical Center, Washington, D.C.

Supported by a grant from ICI Pharmaceuticals Groups, Inc., Wilmington, Delaware.

Presented in part at the Annual Meeting of the American Society of Anesthesiologists, San Francisco, California, October, 1991.

Address correspondence to: Dr. R. Hannallah, Department of Anesthesiology, Children's National Medical Center, 111

Michigan Avenue, N.W., Washington, D.C. 20010.

Accepted for publication 14th September, 1993. recovered faster (22 vs 29-36 $\mathrm{min})(P<0.05)$, were discharged home sooner (101 vs $127-144 \mathrm{~min})(P<0.05)$, and had less postoperative vomiting ( 4 vs $24-48 \%)(P<0.05)$ than all others. There were no serious complications or adverse postoperative sequelae in any of the patients in the study. It is concluded that induction and maintenance of anaesthesia with propofol is a well-tolerated anaesthetic technique in children, and is associated with faster recovery and discharged as well as less vomiting than when halothane is used.

L'objet de cette étude est d'évaluer les changements hémodynamiques à l'induction ainsi que la vitesse et la qualité du réveil, lorsque le propofol (versus thiopental et/ou halothane) est utilisé pour linduction et l'entretien de l'anesthésie d'enfants en ambulatoire. On a étudié 100 enfants dépourvus de traitement, entre 3 et 12 ans, programmés pour une chirurgie ambulatoire. Les chirurgies les plus habituelles sont la cure de strabisme (42\%), la chirurgie plastique (21\%), la restauration dentaire (15\%) et les interventions urologiques (15\%). Les enfants sont distribués aléatoirement pour une anesthésie dinduction/entretien comme suit: propofol/infusion de propofol; propofol/ halothane; thiopental/halothane; halothane pour linduction et l'entretien. On a utilisé la succinylcholine $1,5 \mathrm{mg} \cdot \mathrm{kg}^{-1}$ pour faciliter l'intubation trachéale et le $\mathrm{N}_{2} \mathrm{O} / \mathrm{O}_{2}$ est utilisé comme véhicule gazeux dans tous les cas. Pour l'entretien de l'anesthésie, les agents sont titrés en fonction de la réponse clinique du patient afin de prévoir les mouvements et/ou de maintenir la pression artérielle à $\pm 20 \%$ de la valeur de base. Deux patients (4\%) ont manifesté un inconfort pendant linjection de propofol. La dose moyenne de propofol requise pour prévenir le mouvement est de $267 \pm 83 \mu \mathrm{g} \cdot \mathrm{kg}^{-1} \cdot \mathrm{min}^{-1}$. Autant le profil général des variations hémodynamiques que le moment du réveil (extubation) sont identiques dans les quatre groupes. Les enfants qui reçoivent le propofol se réveillent plus vite (22 secondes versus $29-36 \mathrm{~min}),(P<0,05)$ sont renvoyés plus tôt à la maison (101 versus $127-144 \mathrm{~min})(P<0,05)$ et ont moins de vomissements post-opératoires (4 versus $24-48 \%)(P<0,05)$. Il n'y a pas eu de complications sérieuses ni de séquelles postopératoires chez aucun des patients de l'étude. On en conclut que linduction et l'entretien de l'anesthésie avec le propofol 
est une technique bien tolérée chez l'enfant, associée avec un réveil et un départ plus rapides ainsi que des vomissements moindres que lors de l'utilisation d'halothane.

Propofol (Diprivan ${ }^{\circledR}$ ) is a short-acting intravenous (iv) anaesthetic with high lipid solubility and short elimination half-life. The drug has been investigated extensively for anaesthesia induction and maintenance in adults, but experience with its use for anaesthesia maintenance in children is limited. ${ }^{1-3}$

This study evaluated the haemodynamic changes during induction of anaesthesia, the speed and quality of recovery when propofol was used for induction and maintenance of anaesthesia compared with alternative anaesthetic combinations (propofol induction followed by halothane maintenance, thiopentone induction followed by halothane maintenance, or halothane) in paediatric patients undergoing ambulatory surgical procedures.

\section{Methods}

Institutional approval and parental consent were obtained for this open, comparative, parallel, randomized study. No preoperative sedation was used. Intravenous access was established in conjunction with the required preoperative phlebotomy using a $24-G$ catheter in an antecubital vein.' One hundred 3-12-yr-old children were randomized to receive one of four possible induction/ maintenance combinations. Group 1 patients (PROP/ PROP) received propofol $3.0 \mathrm{mg} \cdot \mathrm{kg}^{-1}$ for induction followed by propofol infusion $50-500 \mu \mathrm{g} \cdot \mathrm{kg}^{-1} \cdot \mathrm{min}^{-1}$. Group 2 patients (PROP/HAL) received the same propofol induction dose followed by halothane $0.5-2 \%$ inspired concentration. Group 3 patients (THIO/HAL) received thiopentone; induction $5 \mathrm{mg} \cdot \mathrm{kg}^{-1}$ followed by halothane 0.5-2\%. Patients in Group 4 (HAL/HAL) received halothane for both anaesthesia induction and maintenance. The induction dose of propofol or thiopentone was administered over $20-30 \mathrm{sec}$, followed immediately by the maintenance drug. Nitrous oxide (60-70\%) was combined with oxygen as the carrier gases in all cases. Vital signs were recorded every minute for the first ten minutes, and every ten minutes thereafter. The first five minutes were allowed to observe the haemodynamic response to induction. This was followed by atropine 0.02 $\mathrm{mg} \cdot \mathrm{kg}^{-1}$, and succinylcholine $1.5 \mathrm{mg} \cdot \mathrm{kg}^{-1}$ to facilitate tracheal intubation. All maintenance drugs were titrated according to the clinical response of the patient to prevent patient movement when this could be safely evaluated without disrupting the surgical procedure, and/or maintain blood pressure within $\pm 20 \%$ of baseline value. When indicated, vecuronium $0.1 \mathrm{mg} \cdot \mathrm{kg}^{-1}$ was used to provide surgical relaxation.
At the conclusion of surgery, bupivacaine $0.25 \%$ was infiltrated around the incision site when appropriate, the anaesthetic agents were discontinued, and the trachea was extubated when the child was fully awake (coughing, gagging, grimacing and moving purposefully). Awakening (extubation) time was calculated from the moment propofol or halothane was turned off until tracheal extubation. Recovery from anaesthesia was objectively evaluated in the Post Anaesthesia Care Unit (PACU) by a research nurse, who was not aware of the anaesthetic sequence, by recording the time required to reach a score of six on the Steward recovery scale. ${ }^{4}$ The Steward recovery scale is based on assessment of three criteria (consciousness, airway, and movement), where a score of 0 to 2 is assigned to each criterion with a maximum total score of 6 when the child is fully awake. The time required to meet home discharge criteria from the Short Stay Recovery Unit (SSRU) was also recorded. ${ }^{5}$ These criteria are: awake and oriented, stable vital signs, no respiratory distress, ambulatory with minimal or no dizziness, and minimal or no nausea or vomiting. The patient's ability to tolerate clear fluids before discharge was also evaluated. A postoperative telephone follow-up call was made to the parents the day following discharge to inquire about the recovery at home. The parents were asked about dizziness, nausea or vomiting, restlessness, being tired and sleepy, depressed, anxious, happy, fearful; suffering from headaches, bad dreams, and inability to concentrate. The occurrence and severity of these were rated on a scale of 0 (none) to 3 (a lot).

Demographic variables were compared among the treatment groups using analysis of variance for continuous variables and chi-square tests for discrete variables. Changes in haemodynamic and respiratory measurements from baseline during induction and maintenance were examined by analysis of covariance with the baseline value as the covariate. Awakening (extubation), recovery and discharge times were compared among treatment groups using analysis of covariance with the total length of anaesthesia as the covariate. The median recovery scores were compared using the Mann-Whitney $U$ test. All statistical tests were two-sided, and resulting $P$ values of $\leq 0.05$ were deemed statistically significant.

\section{Results}

\section{Demographic characteristics}

Twenty-five patients were enrolled in each group. Group 1 patients averaged $7.6 \pm 2.8 \mathrm{yr}$ and weighed $30.4 \pm$ $13.7 \mathrm{~kg}$; Group 2, $7.1 \pm 2.8 \mathrm{yr}$ and $23.7 \pm 11.6 \mathrm{~kg}$; Group 3, $6.3 \pm 3.1 \mathrm{yr}$ and $24.5 \pm 9.9 \mathrm{~kg}$; and Group $4,5.2 \pm 2.3 \mathrm{yr}$ and $19.9 \pm 6.7 \mathrm{~kg}$ respectively. The mean age, weight and height for Group 4 patients was less 
TABLE I Surgical procedures performed

\begin{tabular}{lllll}
\hline & \multicolumn{4}{l}{ Number of patients per treatment group } \\
\cline { 2 - 5 } Type of surgery & $\begin{array}{l}\text { PROP/PROP } \\
(n=25)\end{array}$ & $\begin{array}{l}\text { PROP/HAL } \\
(n=25)\end{array}$ & $\begin{array}{l}\text { THIO/HAL } \\
(n=25)\end{array}$ & $\begin{array}{l}\text { HAL/HAL } \\
(n=25)\end{array}$ \\
\hline Hernia repair & 4 & 0 & 2 & 0 \\
Body surface & 5 & 3 & 3 & 10 \\
Dental/oral surgery & 1 & 5 & 6 & 3 \\
ENT & 3 & 2 & 2 & 2 \\
Orthopaedic & 3 & 5 & 0 & 0 \\
Eye muscle & 10 & 10 & 11 & 11 \\
Urological & 3 & 4 & 2 & 6 \\
\hline
\end{tabular}

*Some patients had more than one procedure.

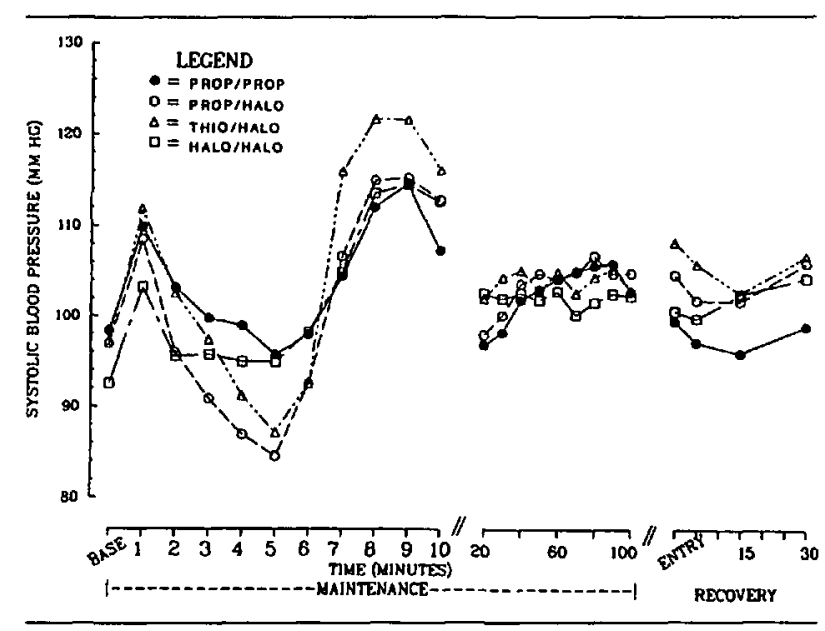

FIGURE 1 changes in systolic blood pressure in the four treatment groups.

than that of the other groups $(P<0.05)$. All patients were ASA Physical Status I or II. The details of the surgical procedures performed are shown in Table I. Eye muscle surgery was the most common procedure performed in all treatment groups.

\section{Anaesthetic induction}

Anaesthesia was successfully induced in all patients in the three $i v$ treatment groups with a single bolus of the designated drug.' There were no differences in the induction times among the groups that were induced with either propofol $(25 \pm 8 \mathrm{sec})$ or thiopentone $(23 \pm 6 \mathrm{sec})$. The induction time was longer $(94 \pm 20 \mathrm{sec})$ in the children in whom anaesthesia was induced with halothane $(P<0.00001)$. Two children $(4 \%)$ complained of pain in the arm during the injection of propofol; however, there were no signs of venous irritation postoperatively.

\section{Anaesthesia maintenance}

The duration of anaesthesia and surgery in all treatment groups is shown in Table I. During the five-minute period that preceded the administration of atropine and succinylcholine, anaesthesia was judged to be adequate in all the THIO/HAL and HAL/HAL patients. One child in the PROP/HAL group required an additional bolus of propofol. Additional boluses of propofol were required in 13 patients in the PROP/PROP group when the infusion rate was started at $<300 \mu \mathrm{g} \cdot \mathrm{kg}^{-1} \cdot \mathrm{min}^{-1}$ to prevent movement during the early phase of maintenance. In the other patients the infusion rate was increased up to $500 \mu \mathrm{g} \cdot \mathrm{kg}^{-1} \cdot \mathrm{min}^{-1}$ for short periods to prevent withdrawal in response to painful stimuli (e.g., starting new $\dot{\nu}$ access). Following tracheal intubation, and when no muscle relaxants were used during maintenance of anaesthesia, the mean propofol dose required to prevent patient movement in response to surgical stimulation was 267 $\pm 83 \mu \mathrm{g} \cdot \mathrm{kg}^{-1} \cdot \min ^{-1}$ (vs $188 \pm 52 \mu \mathrm{g} \cdot \mathrm{kg}^{-1} \cdot \mathrm{min}^{-1}$ when muscle relaxants were used. The adequacy of anaesthesia was evaluated by haemodynamic changes only).

\section{Respiratory and haemodynamic changes}

To insure a smooth transition from induction to maintenance of anaesthesia, respiration was assisted or controlled following loss of eyelash reflex. Therefore, no statistical analyses were done on respiratory rate.

The overall pattern of changes in blood pressure during induction and maintenance was similar for the four treatment groups (Figure 1). Compared with baseline values, the systolic blood pressure increased during the first minute after induction followed by a decrease which was maximal at five minutes. This decrease was greater in the PROP/HAL and THIO/HAL groups than in the PROP/PROP and HAL/HAL groups $(P<0.05)$. The blood pressure reached a peak after tracheal intubation, and then remained relatively stable during the maintenance at a level slightly higher than baseline (Figure 1). The changes in the diastolic and mean pressures followed a similar pattern, except that the decrease observed five minutes after induction was greater in the PROP/HAL 
TABLE II Duration ( $\mathrm{min}$ ) of anaesthesia and surgery, and the times from discontinuation of anaesthetic agents to awakening, recovery and discharge (mean \pm SD)

\begin{tabular}{lccccl}
\hline Treatment group & PROP/PROP PROP/HAL & THIO/HAL & HAL/HAL & $P$ \\
\hline Duration of anaesthesia & $86 \pm 32$ & $97 \pm 35$ & $104 \pm 35$ & $88 \pm 23$ & NS (ANOVA) \\
Duration of surgery & $59 \pm 34$ & $68 \pm 38$ & $75 \pm 32$ & $54 \pm 21$ & NS (ANOVA) \\
Awakening (extubation) & $9 \pm 4$ & $7 \pm 4$ & $11 \pm 5$ & $11 \pm 5$ & NS $\ddagger$ \\
Recovery (PACU) & $22 \pm 12$ & $29 \pm 9$ & $36 \pm 13$ & $31 \pm 11$ & $\mathrm{a}^{*} \ddagger$ \\
Discharge criteria met (no drinking) & $101 \pm 34$ & $133 \pm 50$ & $127 \pm 59$ & $144 \pm 45$ & $\mathrm{~b} \ddagger$ \\
Tolerates po fluids & $116 \pm 39$ & $143 \pm 47$ & $148 \pm 56$ & $169 \pm 57$ & $\mathrm{~b} \ddagger$ \\
\hline
\end{tabular}

*a: $P<0.05$ PROP/PROP vs all others, $P<0.05$ PROP/HAL vs THIO/HAL.

$\dagger$ b: $P<0.05$ PROP/PROP vs all others.

$\ddagger$ Comparison made using analysis of covariance with the total length of anaesthesia as the covariate.

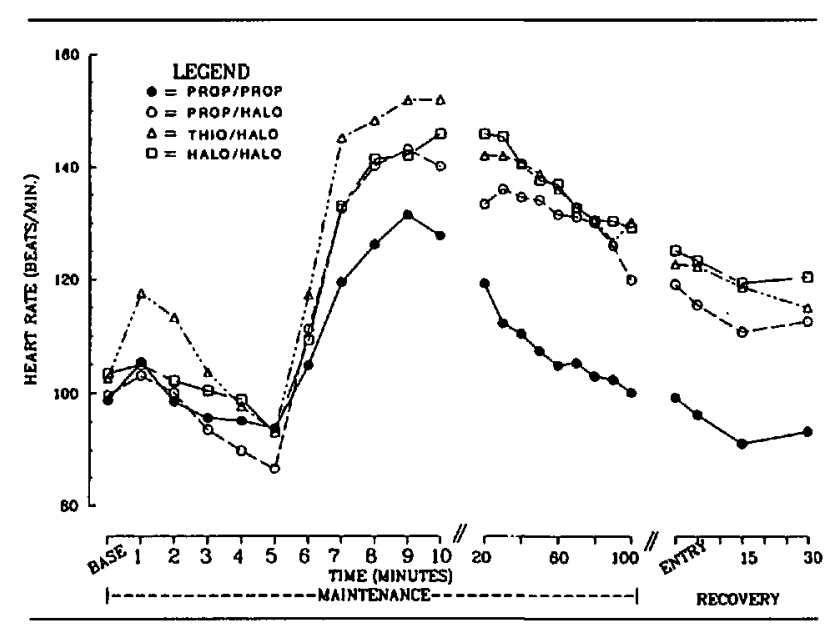

FIGURE 2 Changes in heart rate in the four treatment groups.

group only $(P<0.05)$. The incidence of hypotension, defined as two consecutive (q.5 $\mathrm{min}$ ) systolic blood pressure readings that were at least $20 \%$ below baseline, was not different among the four groups $(8,20,20$, and $8 \%$ in the PROP/PROP, PROP/HAL, THIO/HAL, and HAL/HAL groups respectively).

Heart rate changes during anaesthesia for the four treatment groups are shown in Figure 2. The overall pattern of change was similar for all groups. A slight increase during induction was followed by a decrease which was maximal at approximately five minutes. Following tracheal intubation, which was preceded by the administration of atropine and succinylcholine, heart rate reached a peak, and then decreased slowly throughout the remainder of the anaesthetic course (Figure 2). The increase in heart rate from baseline during maintenance was significantly less in the PROP/PROP group than in the other groups $(P<0.05)$.

\section{Recovery evaluations (Table II)}

Awakening (extubation) times were not different among the four groups. The time course of recovery was faster

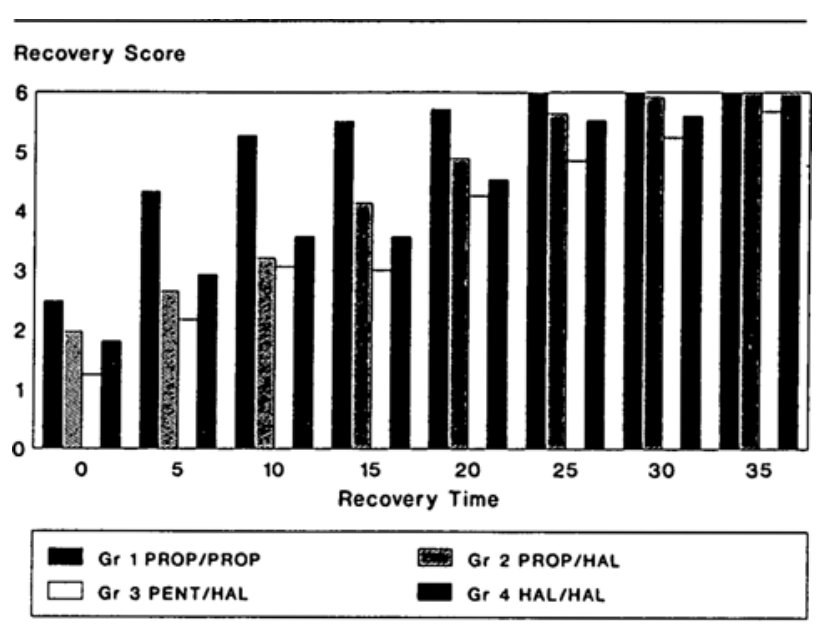

FIGURE 3 Average Stewand recovery score (maximum attainable score $=6$ ) in the PACU. The time course of recovery during the first 15 minutes was significantly faster in the PROP/PROP patients vs all others (Hotelling's $T_{2}+$ test).

(Figure 3) and the recovery time (mean time to reach maximum score of six on the Steward scale) was less in the PROP/PROP group than in the other treatment groups $(P<0.05)$. The time was also less in the PROP/ HAL group than in the THIO/HAL group $(P<0.05)$ but not in the HAL/HAL group. There were no differences in the recovery times between the THIO/HAL and HAL/HAL groups (Table II). Postoperatively, there was no difference in the number of patients who required fentanyl $(4,5,2$, and 3$)$ or acetaminophen $(17,14,20$, and 21) in the PROP/PROP, PROP/HAL, THIO/HAL, and HAL/HAL groups respectively. Children in the PROP/PROP group met home discharge criteria sooner $(P<0.05)$ than those in all the other groups (Table II).

Postoperative vomiting in the hospital was observed in 25\% of all patients (Table II). The incidence of vomiting was less in the PROP/PROP than in the other groups $(P<0.05)$. In the patients who underwent eye 
TABLE III Incidence of postoperative vomiting (\%)

\begin{tabular}{|c|c|c|c|c|}
\hline \multirow[b]{2}{*}{ Treatment group } & \multicolumn{2}{|c|}{ In the Hospital } & \multicolumn{2}{|l|}{ At home $\ddagger$} \\
\hline & $\begin{array}{l}\text { All patients* } \\
(n=I 00)\end{array}$ & $\begin{array}{l}\text { Eye muscle } \\
\text { surg } \dagger(n=40)\end{array}$ & $\begin{array}{l}\text { All patients } \\
(n=82)\end{array}$ & $\begin{array}{l}\text { Eye muscle } \\
\text { surg }(n=35)\end{array}$ \\
\hline PROP/PROP & 4 & 11 & 4 & 11 \\
\hline PROP/HAL & 24 & 33 & 9 & 22 \\
\hline THIO/HAL & 24 & 50 & 17 & 50 \\
\hline HAL/HAL & 48 & 71 & 0 & 0 \\
\hline
\end{tabular}

*Fisher's exact test $P<0.0001$ (PROP/PROP vs HAL/HAL)

$\dagger$ Vomiting was less $(P<0.05)$ in patients who received propofol (PROP/PROP and PROP/HAL) vs those who received thiopentone and/or halothane (THIO/HAL and HAL/HAL).

$\ddagger P<0.05$ (HAL/HAL vs all others).

muscle surgery $(n=42)$, the percent of patients who experienced postoperative vomiting in the hospital was $22.2 \%$ when propofol was used vs $58.8 \%$ when it was not $(P<0.05)$. When propofol was administered for both induction and maintenance, the incidence of postoperative vomiting was $11 \%$. Three patients who vomited in the hospital continued to vomit at home (one in the PROP/PROP and two in the THIO/HAL groups). The incidence of vomiting at home for the 82 patients who were successfully contacted by phone $24 \mathrm{hr}$ after surgery is shown in Table III.

There were no serious complications in the hospital or adverse postoperative sequelae reported by parents in any of the patients in the study.

\section{Discussion}

In this study a single $3 \mathrm{mg} \cdot \mathrm{kg}^{-1}$ bolus of propofol produced rapid and smooth induction of anaesthesia in all children. The onset of anaesthesia was virtually indistinguishable from thiopentone. As has been previously reported, ${ }^{1}$ pain on injection was seen infrequently when propofol was injected into the relatively large antecubital veins. The transition from intravenous induction to acceptance of a face mask delivering $\mathrm{N}_{2} \mathrm{O}$ and halothane was excellent, with only one child requiring an additional bolus of propofol to control excessive movement.

Reports on the propofol maintenance requirements in children are limited. ${ }^{6-9}$ In an attempt to assess the minimal infusion requirement during surgery, we elected to avoid the administration of muscle relaxants unless the surgical requirements dictated their use. This allowed us to administer the lowest infusion rate that maintained blood pressure within $\pm 20 \%$ of baseline value and prevented movement and/or a withdrawal in response to surgical manipulation. The dose of propofol required for maintenance was highly variable and was particularly high (up to $500 \mu \mathrm{g} \cdot \mathrm{kg}^{-1} \cdot \mathrm{min}^{-1}$ in many cases) during the first ten minutes following the induction bolus. This dose is considerably higher than has been reported in adults, ${ }^{10}$ but close to that reported in similar paediatric studies. ${ }^{7}$ This may be partially explained by the fact that, unlike most adult studies, our patients did not receive any sedative or narcotic medications. Moreover, recent studies in children suggest that the kinetics of propofol differ from those in adults. ${ }^{11,12}$ Compared with adults, the volume of the central compartment is approximately $50 \%$ greater, ${ }^{1}$ and the elimination half-life $\left(t_{1 / 2} \beta\right)$ is shorter. ${ }^{12}$

Although considerable cardiovascular depression, manifested as a decrease in blood pressure, is a recognized feature of propofol anaesthesia in adults and in the elderly, ${ }^{13}$ our results showed only a slight decrease of similar magnitude in systolic blood pressure when either propofol or thiopentone induction was followed by halothane maintenance. Because atropine was administered and the trachea was intubated five minutes after induction, only the observations obtained during the first five minutes represent pure drug effects. The decrease in diastolic (and therefore, mean) blood pressure was greater when propofol (vs thiopentone) was followed by halothane. Following the administration of atropine and tracheal intubation, blood pressure increased towards preinduction values as anaesthesia progressed, and no episodes of hypotension occurred. Other studies of the cardiovascular effects of propofol induction in children have found the decrease in blood pressure to be similar to that observed after thiopentone. ${ }^{12}$

The changes in blood pressure were less marked when propofol was used for both induction and maintenance of anaesthesia. There have been previous suggestions that the subsequent administration of halothane may increase the incidence and/or the magnitude of hypotension following propofol induction. ' It is possible that, following $\dot{i}$ induction, the anaesthetist is able to increase inspired halothane concentration more rapidly, and therefore increase the likelihood of hypotension, than when halothane is introduced gradually during inhalational induction. Several mechanisms have been suggested to account for 
hypotension following propofol. ${ }^{14}$ Adult studies point to peripheral vasodilatation resulting in a reduced afterload and/or a decrease in cardiac output secondary to reduced preload. ${ }^{14}$ Although the exact mechanism of hypotension in paediatric patients is unknown, it is likely to be similar to that in adults.

The tendency of propofol anaesthesia to be associated with a slower heart rate than that observed with inhalational agents has been documented in adults. ${ }^{15}$ The same was observed in our patients once the effect of the single dose of atropine given prior to intubation had subsided (Figure 2). This effect on heart rate can be exaggerated if propofol is combined with potent $i v$ opioids or other drugs or manoeuvres (e.g., traction on eye muscles) that are known to produce bradycardia. ${ }^{16}$ The use of $i v$ atropine or a similar anticholinergic agent, is strongly recommended to prevent bradycardia when propofol is used in children.

Previous studies in children have stressed the induction characteristics of propofol, usually followed by an inhalational anaesthetic. The present study showed that the quality of recovery in children undergoing ambulatory surgical procedures using propofol as the principal agent was very satisfactory. Our results in that respect agree with those of Borgeat et al. ${ }^{3}$ who studied children receiving propofol for ENT surgical procedures of short duration. Unlike Borgeat, however, we did not find the awakening (emergence) time, defined as the interval between cessation of drug administration and extubation, to be different when propofol (vs thiopentone/halothane sequence) was used for anaesthetic maintenance. This difference may be explained by the fact that our cases were longer (minimizing the residual effects of the induction dose of thiopentone), and that our propofol infusion rate was higher than was used in patients in the Borgeat study (235 vs $100 \mu \mathrm{g} \cdot \mathrm{kg}^{-1} \cdot \mathrm{min}^{-1}$ ). Following extubation, however, the speed and the rate of recovery were faster in the children whose anaesthesia was induced and maintained with propofol. The shorter recovery times reflect the advantages of a continuous infusion technique when a drug that shows little accumulation is used. Even when an $i v$ induction bolus of propofol was followed by an inhalational maintenance technique $\left(\mathrm{N}_{2} \mathrm{O}\right.$ and halothane), the recovery times were shorter than when thiopentone was used. The faster recovery can be easily explained by the fact that the first stage elimination half-life $\left(t_{1 / 2} \beta\right)$ of propofol is shorter in children than in adults. ${ }^{12}$ The observation that faster recovery also resulted in earlier discharge has not been well documented before. It remains to be seen, however, whether the more rapid discharge from hospital will allow for a reduction in staffing requirements, and therefore offer real pharmacoeconomic benefits. ${ }^{17}$
The most impressive characteristics of recovery following propofol anaesthesia were the lack of drowsiness, and the extremely low incidence of postoperative vomiting, even in patients who underwent procedures known to be associated with vomiting, e.g., eye muscle surgery. ${ }^{8.9}$ Although the incidence of vomiting in our patients was not related to requiring them to drink before discharge, others have shown that forcing children to drink increases the incidence of vomiting and delays discharge. ${ }^{7,18}$ Our findings are different from those of Reimer $e t$ al. in that the earlier discharge that was possible following propofol anaesthesia did not result in a higher incidence of vomiting at home. ${ }^{7}$

In conclusion, the present study shows that continuous infusion of propofol is a well-tolerated anaesthetic technique in children. The speed and quality of recovery after propofol are superior to that observed after thiopentone and/or halothane administration, and are associated with an extremely low incidence of vomiting.

\section{References}

1 Hannallah RS, Baker SB, Casey W, McGill WA, Broadman $L M$, Norden JM. Propofol: effective dose and induction characteristics in unpremedicated children. Anesthesiology 1991; 74: 217-9.

2 Martin TM, Nicolson SC, Bargas MS. Propofol anesthesia reduces emesis and airway obstruction in pediatric outpatients. Anesth Analg 1993; 76: 144-8.

3 Borgeat A, Popovic V, Meier D, Schwander D. Comparison of propofol and thiopental/halothane for short-duration ENT surgical procedures in children. Anesth Analg 1990; 71: 511-5.

4 Steward DJ. A simplified scoring system for post-operative recovery room. Can Anaesth Soc J 1975; 22: 111-3.

5 Hannallah RS, Epstein BS. The pediatric patient. In: Wetchler BV (Ed.). Anesthesia for Ambulatory Surgery, 2nd edition. Philadelphia: JB Lippincott Company, 1991: 184.

6 Morton NS, Wee M, Christie G, Gray IG, Grant IS. Propofol for induction of anaesthesia in children. A comparison with thiopentone and halothane inhalational induction. Anaesthesia 1988; 43: 350-5.

7 Reimer EJ, Bevan JC, Montgomery CJ, Merrick P, Blackstock $D$. Reichert $C$. Does propofol decrease or merely delay post-strabismus repair vomiting in children? Can $\mathrm{J}$ Anaesth 1993; 40: A69.

8 Watcha $M F$, Simeon RM, White PF, Stevens $J L$. Effect of propofol on the incidence of postoperative vomiting after strabismus surgery in pediatric outpatients. Anesthesiology 1991; 75: 204-9.

9 Weir PM, Munro HM, Reynolds PI, Lewis IH, Wilton NCT. Propofol infusion and the incidence of emesis in pediatric outpatient strabismus surgery. Anesth Analg 1993; 76: 760-4. 
10 White M, Kenny GNC. Intravenous propofol anesthesia using a computerized infusion system. Anaesthesia 1990; 45: 204-9.

11 March B, White M, Morton N, Kenny GNC. Pharmacokinetic model driven infusion of propofol in children. $\mathrm{Br} \mathrm{J}$ Anaesth 1991; 67: 41-8.

12 Valtonen $M$, Iissalo E, Kanto J, Rosenberg P. Propofol as an induction agent in children: pain on injection and pharmacokinetics. Acta Anaesthesiol Scand 1989; 33: 152-5.

13 Fahy LT, Van Mourik GA, Utting JE. A comparison of the induction characteristics of thiopentone and propofol (2, 6-di-isopropyl phenol). Anaesthesia 1985; 40: 939-44.

14 Short SM, Aun CST. Haemodynamic effects of propofol in children. Anaesthesia 1991; 46: 783-5.

15 Herregods L, Rolly G, Versichelen L, Rosseel MT.

Propofol combined with nitrous oxide-oxygen for induction and maintenance of anaesthesia. Anaesthesia 1987; 42: $360-5$.

16 Egan TD, Brock-Utne JG. Asystole after anesthesia induction with a fentanyl, propofol, and succinylcholine sequence. Anesth Analg 1991; 73: 818-20.

17 Bevan DR. Anaesthesia pharmacoeconomics (Editorial). Can J Anaesth 1993; 40: 693-5.

18 Schreiner MS, Nicolson SC, Martin T, Whitney L. Should children drink before discharge from day surgery? Anesthesiology 1992; 76: 528-33. 